\title{
Assessing the meridional atmosphere and ocean energy transport in a varying climate
}

\author{
YANG HaiJun \\ Laboratory for Climate and Ocean-Atmosphere Studies, Department of Atmospheric and Oceanic Sciences, School of Physics, Peking University, \\ Beijing 100871, China
}

Received November 19, 2012; accepted December 18, 2012; published online February 25, 2013

\begin{abstract}
Assessing the meridional atmosphere and ocean energy transport is one of the most classical problems in climate research. The meridional energy transport plays a critical role in maintaining the equilibrium of the earth system. Although the principle to calculate the meridional energy transport is simple, many fundamental questions remain unsolved. For example, what are the intrinsic mechanisms to maintain the hemispherically antisymmetric structure in the total energy transport? How on earth does the meridional energy transport partition between the atmosphere and ocean and, is there really a so-called "Bjerknes compensation" relationship between them? This relationship would provide us deep insight into the coupling mechanisms between the ocean and atmosphere in global scale. In this review we try to come out some important problems that are deserved in-depth investigations in current climate studies.
\end{abstract}

meridional energy transport, Bjerknes compensation, coupling mechanisms

Citation: Yang H J. Assessing the meridional atmosphere and ocean energy transport in a varying climate. Chin Sci Bull, 2013, 58: 1737-1740, doi: 10.1007/ s11434-013-5665-x

Assessing the meridional heat transport (MHT) in the climate system is an "old" question. The atmosphere and the ocean transport heat from the equator to the poles, maintaining a stable earth climate. The total MHT is usually calculated by integrating the observed net radiative fluxes, which is defined as the difference between the downward shortwave radiation and the outgoing longwave radiation (OLR) at the top of the atmosphere (TOA). The MHT was estimated as early as the 1970s by probably the work of Vonder Haar and Oort [1] when the satellite observation of the radiative fluxes first became available. Afterwards it has been calculated by many researchers [2-12]. The most reliable estimates of the global radiation to and from space are believed to be from the Earth Radiation Budget Experiment (ERBE) and Nimbus-7 satellite measurements [9], which give a robust picture that the combined atmosphere-ocean system is maintained by an antisymmetrical poleward heat

email: hjyang@pku.edu.cn transport with the peak value of about $\pm 5.5 \mathrm{PW}(1 \mathrm{PW}=$ $10^{15} \mathrm{~W}$ ) at $35^{\circ} \mathrm{N} / \mathrm{S}$ (Figure 1) [11,12].

The partitioning of the total poleward heat transport by the atmosphere and ocean is the central element in describing and understanding the climate and its change [12]. The atmospheric heat transport (AHT) is usually estimated from observations directly using 3-D atmospheric variables and the oceanic heat transport (OHT) is obtained by subtracting the AHT from the total. The later approach is an indirect approach that is used in most studies since direct oceanic observations are sparse. This procedure assumes that the atmospheric observations are correct over both land and ocean [11]. The general picture of the partitioning of the total heat transport between the atmosphere and ocean is that, the AHT dominates poleward of about $30^{\circ} \mathrm{N} / \mathrm{S}$ while the OHT dominates in the deep tropics (Figure 1) [12-14]. More specifically, the poleward AHTs peak at $43^{\circ} \mathrm{N}\left(40^{\circ} \mathrm{S}\right)$ with the value of $5.0 \pm 0.14 \mathrm{PW}$. At $35^{\circ} \mathrm{N} / \mathrm{S}$ where the peak total poleward transport occurs, the AHT accounts for $78 \%$ 


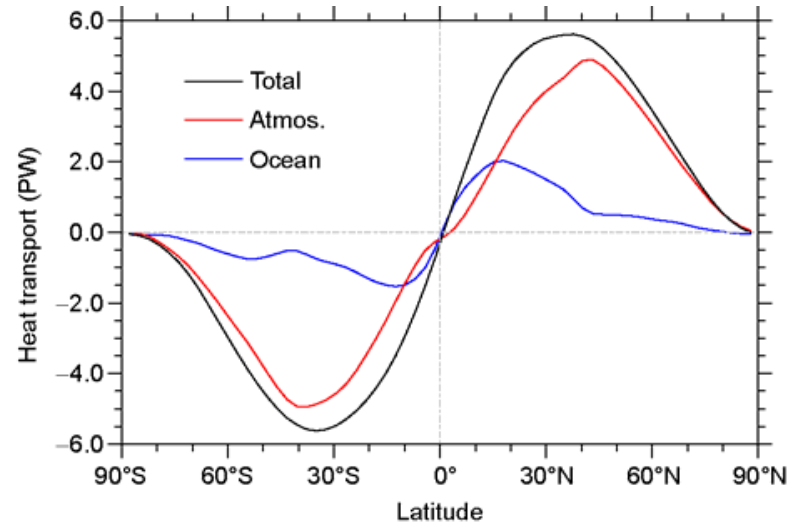

Figure 1 The meridional heat transport [11]. The red, blue and black lines are for the atmosphere, ocean and total heat transport of the earth system. The total heat transport is calculated from the net radiation flux at the top of atmosphere. The atmosphere heat transport is derived from the ERA40 data. The ocean heat transport is the residual of the total and atmosphere.

(92\%) of the total in the Northern (Southern) Hemisphere [11]. However, the OHT increases toward the tropics and it is even larger than the AHT near the equator. The oceanic component reaches a maximum value of somewhat less than $2 \mathrm{PW}$ in the Northern Hemisphere (NH) lower latitudes. The oceanic transport in the Southern Hemisphere (SH) is much weaker, mainly due to the equatorward South Atlantic transport that reduces the oceanic contribution to the total poleward flux [12].

\section{Problems}

The "old" heat transport problem has been revived in recent years, particularly because the varying climate, say, the global warming we are experiencing now, drives us to rethink some fundamental questions on the earth energy balance. For examples, there are still open questions on the mean heat transport profiles that were thought to be well accepted. (1) Why is the total energy transport almost hemispherically antisymmetric, despite the great asymmetry of the oceanic heat fluxes [12]? (2) What is the "real" oceanic contributions to the total heat transport in the mid-high latitudes, considering that much of atmospheric transport is in the form of the transport of latent heat which is essentially maintained by the water vapour supply from the ocean?

The first question arises from the fact of the significant difference in ocean-land contrast between the $\mathrm{NH}$ and the $\mathrm{SH}$. The OHT estimated from the observations is very weak in the SH. This is something of an artefact: the South Atlantic transport is equatorward, counteracting the southward transport in the South Pacific and Indian oceans, thus reducing the contribution to the total poleward flux $[11,12]$. Despite this hemispheric asymmetry, the combined oceanatmosphere transports are remarkably latitude antisymmetric. Why and how this antisymmetry is maintained by the combined system is not so clear. Some studies have suggested that a negative feedback between the atmosphere and ocean transports: if the oceanic heat flux weakens, the atmospheric flux would compensate [15]. However, the negative feedback is unclear, and precisely how it would so compensate is less clear.

The second question remains important because accurate estimate of the OHT is hampered by the short and sparse oceanic observations. There are big uncertainties in the current OHT from both the direct and indirect estimates. For oceanic fraction in the mid-latitudes, earlier it was thought to be about $50 \%$ of the total in the $\mathrm{NH}$ [10], but more recently it was thought to be as low as $10 \%$ of the total [11], as estimates of direct global OHTs emerged [16]. However, "because much of the flux in the atmosphere is in the form of the transport of latent heat, and because the ocean carries an equivalent amount of water, much of the heat flux commonly assigned to the atmosphere is actually in a combined mode of both systems $[12,16]$ ". A detailed diagnostics on the atmospheric mass transport suggests that, neglecting the latent heat contribution, the air mass transport in the midlatitudes would be reduced by as much as $80 \%$ [14]. The ocean contributes a big amount to the moist static energy in the atmosphere and thus should be considerably involved in the atmospheric energy transport. A re-estimate of the ocean partition in the mid-high latitudes is quite needed.

Besides the above questions on the mean climate, there are many questions on the changes in the meridional atmosphere and ocean transport in a varying climate. This is one of research frontiers in the climate change studies and has drawn great attentions internationally in recent years. During the past 30 years many works investigated poleward heat transport and the partitioning of the atmospheric and oceanic components, but few has paid attention to an equally important issue - the variability of heat transport in both components, probably due to lack of the long-term reliable measurements of the heat fluxes. This is of importance since a change in the heat transport could correspond to a large climate shift [17]. Suppose under certain circumstance, the total meridional heat transport is reduced by $10 \%$, which is about $0.5 \mathrm{PW}$ of the total 5-6 PW. This corresponds to a $9 \mathrm{~W} \mathrm{~m}^{-2}$ decrease in the atmosphere radiation flux for the region of north of $40^{\circ} \mathrm{N}$ of the Earth surface [12]. This is far beyond any plausible estimate of ongoing global warming. The doubled atmospheric $\mathrm{CO}_{2}$ corresponds to 3-4 $\mathrm{W} \mathrm{m}^{-2}$. The effect of human activities since 1750 corresponds to a mean radiative forcing of 1.6 [0.6 to 2.4$] \mathrm{W} \mathrm{m}^{-2}$ [18]. It is not hard to imagine the small change in the heat transport could result in significant regional climate change.

The heat transport problem has received fresh attentions also partly because of the profound impact of the changes in the Atlantic meridional overturning circulation (AMOC) on the global climate. Observations have evidenced that there are strong short-term variabilities in the AMOC ranging from 4.0 to $34.9 \mathrm{~Sv}$ [21]. The mean AMOC and its standard 
deviation are comparable in magnitudes. This casts the doubt on the arguments that "the AMOC had decreased by $30 \%$ and the northward heat transport decreased by over $20 \%$ " based on in-situ observations near $25^{\circ} \mathrm{N}$ between 1957 and 2004 [19,22]. Such a big change in ocean circulation appears to be consistent with the significant dilution in the Northern North Atlantic Ocean [20]. However, the observed change - as Bryden et al. [19] cautioned-was uncomfortably close to the uncertainties in the current observational estimates [21,22]. This raises the urgency for a deeper understanding of the mechanism of the heat transport variability in the atmosphere-ocean system.

For a steady climate without external heat forcing to the earth climate, the changes in the atmospheric and oceanic transports tend to be compensated on decadal and longer time scales-this is called "Bjerknes compensation" [17,23,24]. In the 1960s, Jacob Bjerknes [25] suggested that if the TOA fluxes and the oceanic heat storage did not vary too much, the total energy transport by the climate system would not vary too much either. This implies that any large variations of oceanic and atmospheric energy transport should be equal and opposite. This simple scenario has become known as Bjerknes compensation. It would be a critical constraint that might reduce the degree of freedom or uncertainty of the climate system. It also implies that the decreased northward oceanic transport noted in Bryden et al. [19] would be more or less compensated by the increased northward atmospheric transport, such that the total northward heat transport does not change too much, so the climate in the northern high latitudes.

The hypothesis of "Bjerknes compensation" is deserved to explore extensively and thoroughly. Unfortunately this neat assumption is only identified in one coupled model so far [17] and has not been investigated in observations and other coupled models. The "rightness" of Bjerknes compensation will enhance our understanding of the coupled climate system. However, there are some fundamental controversies on the applicability of Bjerknes compensation. For instance, it was initially found to be only valid in the northern high latitudes [17,23], while recently it was found to be only valid in the tropics [24]. The latter also contradicts with the framework on the tropical ocean and atmosphere partitions [13], which indicates that the AHT and OHT would change in the same direction instead of opposite direction. In addition, present studies suggest that the Bjerknes compensation is limited to the $\mathrm{NH}$, and further to the Western Hemisphere. It needs explicit explanations why the Bjerknes compensation is unclear in the whole $\mathrm{SH}$ as well as in the Northern Eastern Hemisphere. One can refer to Vallis and Farneti [26] for the advance in the atmosphere and ocean heat transport studies in the varying climate in details.

During the last year (2011-2012), the studies of Bjerknes compensation in the MHT have made great strides. Using several different updated coupled climate models (NCAR CESM1.0 and GFDL CM2.1), Yang et al. [27] systemati- cally examined the effect of fresh water forcing and wind forcing on the MHT. The sensitivity experiments showed that the total MHT of the Earth system does not change too much under both the fresh water hosing and perturbation wind forcing, which assured the precondition for the validity of the Bjerknes compensation. The decrease in the OHT is almost compensated by the increase in the AHT, and this compensation is valid nearly in all latitudes, which is different from previous studies. In the water hosing experiments [27], the weakening of AMOC reduces the northward Atlantic OHT significantly. This leads to a warming (cooling) in SST in the Southern (Northern) Hemisphere and in turn a southward shift of atmospheric convection. This enhances the Hadley cell and thus the northward AHT, compensating the reduced Atlantic OHT. In the wind perturbation experiments (unpublished data), shutting down the global surface winds causes significant reductions in both the wind-driven circulation and the thermohaline circulation, resulting in remarkable decrease in the poleward oceanic heat transport. The SST responds with significant warming in the equator and cooling off the equator, which feeds back to the atmosphere and causes the Hadley Cell move equatorward with an enhanced intensity. This in turn increases the meridional atmospheric heat transport, compensating the decrease of the poleward oceanic heat transport. These studies focus on the adjustment of the large-scale ocean and atmosphere circulations to the external forcing, and emphasize that the ocean changes lead the atmosphere changes. This assures the opposite changes in the ocean and atmosphere circulations and thus the compensation between the changes in the OHT and AHT.

The up-to-date studies by Farneti and Vallis [28] show the similar results. Using a state-of-art coupled climate model (GFDL CM2.1), an intermediate complexity climate model (GFDL ICCM) and a simple energy balance model (EBM), they examined the compensation of AHT and OHT in the frame work of internal climate variability. On decadal and longer time scales, a high degree of compensation between the energy transport in the atmosphere and ocean is found the Northern Hemisphere in the Atlantic sector. They argue that compensation can best be interpreted as arising from the highly efficient nature of the energy transport in the atmosphere rather than any a priori need for the top-of-atmosphere radiation budget to be fixed. The biggest problem in these new researches is that the cloud radiation effect as well as the cloud-radiation feedback is not explored at all, so that our understanding on the mechanisms of the Bjerknes compensation is incomplete.

\section{Research focus in the future}

The structure and maintain mechanism of the MHT in the Earth system need to be explored in-depth, in which the relationship between the variations of AHT and OHT should 
be examined thoroughly. In a steady climate, we should first make clear what maintain the hemispheric antisymmetric feature of the total MHT and why this feature is not disturbed be the significant difference in the ocean-continent contrast in the two hemispheres. What is the real contribution of the OHT, particularly the OHT in the mid-high latitudes, to the total MHT? What are the relative contributions of the wind-driven circulation and thermohaline circulation to the OHT? How to quantify the effects of the ocean mesoscale eddies, submeso-scale eddies and dissipation on the OHT? These problems are so challenging that eddy-resolved coupled climate model has to be employed.

In the studies of the natural variability of the MHT, special attention should be paid to the decadal and longer timescale variability. The validity of the Bjerknes compensation between the AHT and OHT has to be confirmed first using observational data and coupled models. Then the structure of the Bjerknes compensation should be explored, which includes the compensation rate (see definition in Swaluw et al. [17]) and the latitude bands that the compensation works. The dynamic and thermodynamic processes resulting in the compensation should be identified. Under the circumstance of no external thermal forcing to the Earth system, would the compensation still be valid if there is significant shift in the Earth mean climate? If so, how would the large scale atmospheric and oceanic circulation adjust to the climate shift in order to keep the total MHT unchanged?

In the current climate undergoing a long term trend (such like global warming), how the MHT in the Earth system adjusts, and whether the Bjerknes compensation is still valid are critical to us to understand the future climate change. If it still works, the Bjerknes compensation may play an important constraint mechanism that would limit any significant shift in the climate system. This implies that the future climate in a whole would not change too much, and thus provides invaluable information to the policymaker and ordinary people. In general, assessing the meridional atmosphere and ocean energy transport in a varying climate can not only deepen our understanding of the coupled processes in the Earth climate system, but also enlighten on the way to predict the future climate change.

This work was supported by the National Natural Science Foundation of China (40976007 and 41176002), the National Basic Research Program of China (2012CB955201) and the Special Fund for Meteorological Scientific Research in the Public Interest of China Meteorological Administration (GYHY201006022).

1 Vonder Haar T H, Oort A H. A new estimate of annual poleward energy transport by the oceans. J Phys Oceanogr, 1973, 3: 169-172

2 Oort A H, Vonder Haar T H. On the observed annual cycle in the ocean-atmosphere heat balance over the Northern Hemisphere. J Phys Oceanogr, 1976, 6: 781-800

3 Trenberth K E. Mean annual poleward energy transports by the oceans in the Southern Hemisphere. Dyn Atmos Oceans, 1979, 4: 57-64

4 Masuda K. Meridional heat transport by the atmosphere and the ocean; Analysis of FGGE data. Tellus, 1988, 40A: 285-302

5 Carissimo B C, Oort A H, Vonder Haar T H. Estimating the meridional energy transports in the atmosphere and ocean. J Phys Oceanogr, 1985, 15: 82-91

6 Savijärvi H I. Global energy and moisture budgets from rawinsonde data. Mon Weather Rev, 1988, 116: 417-430

7 Michaud R, Derome J. On the mean meridional transport of energy in the atmosphere and oceans as derived from six years of ECMWF analyses. Tellus, 1991, 43A: 1-14

8 Peixoto J P, Oort A H. Physics of Climate. Maryland: American Institnte Physics, 1992. 520

9 Bess T D, Smith G L. Earth radiation budget: Results of outgoing longwave radiation from Nimbus-7, NOAA-9, and ERBS satellites. J Appl Meteor, 1993, 32: 813-824

10 Trenberth K E, Solomon A. The global heat balance: Heat transports in the atmosphere and ocean. Clim Dyn, 1994, 10: 107-134

11 Trenberth K E, Caron J M. Estimates of meridional atmosphere and ocean heat transports. J Clim, 2001, 14: 3433-3443

12 Wunsch $\mathrm{C}$. The total meridional heat flux and its oceanic and atmospheric partition. J Clim, 2005, 18: 4374-4380

13 Held I M. The partitioning of the poleward energy transport between the tropical ocean and atmosphere. J Atmos Sci, 2001, 58: 943-948

14 Czaja A, Marshall J. The partitioning of poleward heat transport between the atmosphere and ocean. J Atmos Sci, 2006, 63: 1498-1511

15 Stone P H. Constraints on dynamical transports of energy on a spherical planet. Dyn Atmos Oceans, 1978, 2: 123-139

16 Bryden H L, Imawaki S. Ocean heat transport. Ocean Circulation and Climate. New York: Academic Press, 2001. 455-474

17 Swaluw E, Drijfhout S S, Hazeleger W. Bjerknes compensation at high northern Latitudes: The ocean forcing the atmosphere. J Clim, 2007, 20: 6023-6032

18 IPCC. Climate Change 2007: The Physical Science Basis Summary for Policymakers. Contribution of Working Group I to the Fourth Assessment Report of the Intergovernmental Panel on Climate Change. Cambridge, United Kingdom and New York: Cambridge University Press, 2007. 996

19 Bryden H L, Longworth H R, Cunningham S A. Slowing of the Atlantic meridional overturning circulation at $25^{\circ} \mathrm{N}$. Nature, 2005, 438: 655-657

20 Curry R, Mauritzen C. Dilution of the Northern North Atlantic Ocean in recent decades. Science, 2005, 308: 1772-1774

21 Cunningham S A, Kanzow T, Rayner D, et al. Temporal variability of the Atlantic meridional overturning circulation at $26.5^{\circ} \mathrm{N}$. Science, 2007, 317: 935-938

22 Church J A. A change in circulation? Science, 2007, 317: 908-909

23 Shaffrey L C, Sutton R T. Bjerknes compensation and the decadal variability of the energy transports in a coupled climate model. $\mathrm{J}$ Clim, 2006, 19: 1167-1181

24 Vellinga M, Wu P. Relations between northward ocean and atmosphere energy transport in a coupled climate model. J Clim, 2008, 21: 561-575

25 Bjerknes J. Atlantic air-sea interaction. Adv Geophys, 1964, 10: 1-82

26 Vallis G K, Farneti R. Meridional energy transport in the atmosphere-ocean system: Theory and numerical experiments. Q J R Meteorol Soc, 2009, 135: 1643-1660

27 Yang H, Wang Y, Liu Z. Compensation of meridional heat transport: Testing the Bjerknes hypothesis in a freshening ocean. Tellus, 2013, in press

28 Farneti R, Vallis G K. Meridional energy transport in the coupled atmosphere-ocean system: Compensation and partitioning. J Clim, 2013 , in press

Open Access This article is distributed under the terms of the Creative Commons Attribution License which permits any use, distribution, and reproduction in any medium, provided the original author(s) and source are credited. 